\title{
BMJ Open Prevalence and factors associated with modern contraceptive use among women of reproductive age in 20 African countries: a large population- based study
}

\author{
Paschal Awingura Apanga (D) , ${ }^{1}$ Maxwell Tii Kumbeni, ${ }^{2}$ Emmanuel Awine Ayamga, ${ }^{2}$ \\ Mark B Ulanja, ${ }^{3}$ Robert Akparibo ${ }^{4}$
}

To cite: Apanga PA, Kumbeni MT, Ayamga EA, et al. Prevalence and factors associated with modern contraceptive use among women of reproductive age in 20 African countries: a large populationbased study. BMJ Open 2020;10:e041103. doi:10.1136/ bmjopen-2020-041103

- Prepublication history for this paper is available online To view these files, please visit the journal online (http://dx.doi. org/10.1136/bmjopen-2020041103).

Received 30 May 2020 Revised 19 July 2020 Accepted 24 July 2020

Check for updates

(C) Author(s) (or their employer(s)) 2020. Re-use permitted under CC BY-NC. No commercial re-use. See rights and permissions. Published by BMJ.

${ }^{1}$ School of Community Health Sciences, University of Nevada, Reno, Nevada, USA

${ }^{2}$ Nabdam District Health

Directorate, Ghana Health

Service, Nangodi, Upper East Region, Ghana

${ }^{3}$ School of Medicine, University of Nevada, Reno, Nevada, USA

${ }^{4}$ School of Health and Related Research, The University of Sheffield, Sheffield, UK

Correspondence to Dr Paschal Awingura Apanga; awingura@yahoo.com

\section{ABSTRACT}

Objective To assess the prevalence and factors associated with modern contraceptive (CP) use among women of the reproductive age.

Design Cross-sectional study.

Setting We used data from the Multiple Indicator Cluster Surveys (MICSs) from 20 African countries collected between 2013 and 2018.

Participants Data on 1177459 women aged 15-49 years old.

Methods Multivariable logistic regression was used to identify factors associated with modern CP use, while controlling simultaneously for independent variables, and accounting for clustering, stratification and sample weights from the complex sampling design. We used random effects meta-analysis to pool adjusted estimates across the 20 countries.

Results The overall prevalence of modern CP use was $26 \%$ and ranged from $6 \%$ in Guinea to $62 \%$ in Zimbabwe. Overall, injectable (32\%) was the most preferred method of CP, followed by oral pill $(27 \%)$ and implants $(16 \%)$. Women were more likely to use a modern CP if they: had a primary (adjusted prevalence odds ratios (aPORs): $1.68,95 \% \mathrm{Cl}$ : 1.47 to 1.91)) or secondary/higher education (aPOR: $2.16,95 \% \mathrm{Cl}: 1.80$ to 2.59 ) compared with women with no formal education; had no delivery in the last 2 years (aP0R: 3.89, 95\% Cl: 2.76 to 5.47) compared with women who delivered in the last 2 years; were aged 25-34 years (aPOR: $1.33,95 \% \mathrm{Cl}: 1.20$ to 1.47) compared with women aged 15-24 years; were of middle-income status (aPOR: $1.25,95 \% \mathrm{Cl}: 1.11$ to 1.39 ) or rich (aPOR: $1.53,95 \% \mathrm{Cl}$ : 1.27 to 1.84) compared with poor women and had two or more antenatal care visits compared with women without a visit. Perceived domestic violence was not associated with modern CP use (aPOR: 0.98, 95\% Cl: 0.92 to 1.05). Conclusion Our findings are relevant in a global context, particularly in the African region, and improve our understanding on relevant factors essential to increasing modern $\mathrm{CP}$ use.

\section{BACKGROUND}

Modern contraceptives (CPs) have been identified as an effective method for fertility
Strengths and limitations of this study

- This study draws from many representative household surveys from countries within the African region, and therefore our findings should be generalisable to many of the countries within the region.

- Pooled analysis was suitable for making our findings generalisable across many countries.

- The current findings are useful to inform intervention development to improve contraceptive coverage.

The findings of our study cannot establish causality.

reduction, and are thus being widely promoted to slow rapid population growth, particularly in developing countries. ${ }^{1-3}$ Promoting access to modern CPs among women of reproductive age has also proven to be an effective public health intervention to improve maternal and child health outcomes. ${ }^{45}$ There is a plethora of research evidence demonstrating that increase in CP use directly averts maternal mortality by preventing unplanned pregnancies, teenage pregnancy, unsafe abortions, high-risk pregnancies and allows for spacing of pregnancies. ${ }^{146}$ Some modern CPs, such as condom use, have been lauded not only for family planning purposes, but also for their role in preventing sexually transmitted infections including HIV/AIDS. ${ }^{1}$ Modern CP methods are also essential to help nations achieve the Sustainable Development Goal five, which aims at achieving gender equality and empowering all women and girls. ${ }^{7}$

Globally, the demand and use of modern CPs has increased in most countries. ${ }^{8}$ However, its acceptor rate remains low, and there is persistently high unmet need for family planning among women in developing countries despite its overwhelming benefits. ${ }^{1}$ Data available have shown that the prevalence 
of modern CP use among married women or those in relationships in Africa was low: estimated at 23.9\% in 2012 and $28.5 \%$ in $2017 .{ }^{9}$ Studies have also reported low utilisation of modern CPs in Africa among women in their reproductive age. ${ }^{1011}$

There are mixed findings in terms of the factors influencing the low use of modern CPs among women in Africa. Studies have established strong associations between higher socioeconomic status and modern $\mathrm{CPs}$, and between being married and an increase use of modern CPs, ${ }^{3}{ }^{12}$ but these findings were inconsistent with others from the African region. ${ }^{13} 14$ This suggests that modern CP use might also differ across different sociocultural contexts. ${ }^{15}$ Additionally, previous studies on modern CP use in Africa have focused on individual countries. ${ }^{1016}$ Very few have been equipped to assess the prevalence and drivers of modern CP use across Africa. ${ }^{11}$ Again, none of these studies have considered meta-analysing the data on $\mathrm{CP}$ use for us to better understand the overall prevalence of modern CP use in the African region.

The aim of our study therefore was to assess the prevalence and factors associated with modern CP use among women of reproductive age using a large populationbased survey from the 20 African countries. The research findings will be relevant in a global context, particularly within the African region to improve maternal and child health outcomes by improving the use of modern CPs among women of the reproductive age.

\section{METHODS}

\section{Study population and data source}

We used data from the Multiple Indicator Cluster Surveys (MICSs) from the 20 African countries from 2013 to 2018. These countries include; Ghana, Democratic Republic of Congo (DRC), Gambia, Lesotho, Madagascar, Sierra Leone, Togo, Tunisia, Benin, Guinea Bissau, Guinea, Cameroon, Côte d'Ivoire, Kenya, Malawi, Mali, Mauritania, Nigeria, Sudan and Zimbabwe. MICS is a UNICEF-led cross-sectional nationally representative household study conducted in many countries, and provides robust data on women, men and children. The survey measures key indicators that are considered relevant to allow countries to generate data that can be used to inform policy and practice. ${ }^{17}$ We limited our study population to only women aged $15-49$ years old.

The MICS uses a two-stage sampling procedure that involves selection of census enumeration areas from each sampling strata using a probability proportional to size of the number of households in each enumeration area in the first stage. In the second stage, households are sampled using systematic random sampling from each enumeration areas, which forms the survey clusters. A detailed description of the MICS sampling design and data collection procedures have been published elsewhere. ${ }^{1819}$

\section{Primary outcome}

The primary outcome of interest was the current use of modern $\mathrm{CP}$ among women of the reproductive age (15-49 years). Modern CP use was dichotomised as ' 1 ' for a woman currently using any modern CP method, and ' 0 ' for those who reported not using modern CPs. Use of modern CP was defined as currently using any of the following CP methods: sterilisation (male or female), intrauterine device (IUD), injectable, implant, pills, condom (male or female), diaphragm and foam/jelly. Our definition of modern CPs was adopted from the Guttmacher Institute. ${ }^{20}$ This definition has been used to guide data collection and analysis in several similar studies. ${ }^{21-24}$

\section{Independent variables}

The independent variables in our study were: age, marital status, educational level, health insurance status, delivery period, parity, antenatal care attendance in the last 2 years, residency status, wealth status, media use and perceived domestic violence. Age was categorised as: 15-24, 25-34 and 35-49 years with 15-24 years as the reference category. The remaining variables were categorised as follows: marital status (never married=' 1 ', married/union='0'); educational level (secondary or higher education='2', primary education=' 1 ', no formal education $={ }^{\prime} 0$ '); health insurance status (no insurance $={ }^{\prime} 1$ ', insurance $={ }^{\prime} 0$ '); delivery period (no delivery in the last 2 years=' 1 ', delivery in the last 2 years='0'); parity (nulliparous $=$ ' 1 ', parous $={ }^{\prime} 0$ ' $)$, antenatal care attendance $\left(\geq 4={ }^{\prime} 4\right.$ ', $3={ }^{\prime} 3 ', 2={ }^{\prime} 2 ', 1={ }^{\prime} 1 ', 0={ }^{\prime} 0$ ') and residency status (rural=' 1 ', urban $={ }^{\prime} 0$ '). We used wealth quintiles to construct our wealth status variable. The upper two, middle and lower two wealth quintiles were used to denote rich, middle income and poor (reference value), respectively. Media use was when a woman reported any of the following: read the newspaper/magazine, listened to radio, watched television or used the internet at least once a week or almost every day. Women who used the media were assigned as the reference category (' 0 '), while those who did not use the media were coded as ' 1 '. Perceived domestic violence was also dichotomised as: perceived domestic violence $={ }^{\prime} 1$ ' and no perceived domestic violence $={ }^{\prime} 0$ '. Perceived domestic violence was defined as any woman who reported that her husband/partner will not be justified in beating/hitting her if she committed any of the following events: if she goes out without telling him; if she neglects the children; if she argues with him; if she refuses to have sex with him and if she burns the food.

\section{Data analysis}

Descriptive statistics and multivariable logistic regression was conducted using SAS V.9.3 (SAS Institute), while random effects meta-analysis was performed using Stata V.16 SE (Stata Corp, College Station, Texas, USA). All data sets for each country were checked to ensure that they had the variables of interest prior to the analysis. We used descriptive statistics to determine the prevalence of modern CPs, and the type of modern CP method in 
each country. We also conducted a multivariable logistic regression controlling simultaneously for all independent variables to estimate the adjusted prevalence odd ratios (aPORs) for all variables. Missing data were dropped. In all descriptive and multivariable logistic regression analysis, we accounted for clustering, stratification and applied sampling weights from the complex sampling design to ensure representativeness with each country.

\section{Synthesis of results across the $\mathbf{2 0}$ countries}

A random effects meta-analysis was used to synthesise the results in view of the substantial heterogeneity across different populations. Statistical heterogeneity was reported using the $\mathrm{I}^{2}$ statistics. An estimate of $\mathrm{I}^{2}>50 \%$ was considered to be of substantial heterogeneity, and an estimate of $\mathrm{I}^{2}>75 \%$ may be of considerable heterogeneity. ${ }^{25}$ The random effects meta-analysis was used to pool the estimates of: the prevalence of modern CP use, prevalence of method of modern CP use and aPORs for independent variables across all the 20 countries using inverse-variance weighing. We present our results stratified by each country and overall using forest plots.

\section{Patient and public involvement}

Patients and/or the public were not involved in the design, or conduct, or reporting, or dissemination plans of this research as we used secondary data.

\section{RESULTS}

\section{Study sample and prevalence of modern CPs}

A total of 1177459 women aged 15-49 years were included in our study. The data from the 20 countries ranged from 2013 to 2018 with only one MICS survey for each country (table 1). The overall prevalence of modern CPs use was $26 \%$ (95\% CI: $18 \%$ to $34 \%$ ). Zimbabwe had the highest prevalence of modern CP use, $62 \%$ (95\% CI: $61 \%$ to $63 \%)$. This was followed by Malawi (56\%, $95 \%$ CI: $55 \%$ to $57 \%$ ), Kenya ( $56 \%, 95 \%$ CI: $52 \%$ to $60 \%$ ), Lesotho (55\%, 95\% CI: $53 \%$ to $57 \%)$, Tunisia $(50 \%, 95 \%$ CI: $49 \%$ to $52 \%$ ) and Madagascar (35\%, 95\% CI: $34 \%$ to $37 \%$ ). Guinea (6\%, 95\% CI: $5 \%$ to $7 \%)$ reported the lowest use of modern CPs (figure 1). There was high heterogeneity on the prevalence of modern $\mathrm{CP}$ use across all countries $\left(\mathrm{I}^{2}=99.9 \%\right.$, $\mathrm{p}$ value $\left.<0.001\right)$.

With regards to methods of modern CPs (figures 2 and 3 ), overall highest prevalence of the method of modern CPs was injectable (32\%, 95\% CI: $22 \%$ to $42 \%)$, followed by pills $(27 \%, 95 \%$ CI: $18 \%$ to $37 \%)$, implants $(16 \%$, 95\% CI: $12 \%$ to $20 \%)$ and condoms (15\%, $95 \%$ CI: $13 \%$ to $18 \%$ ). Injectable was a more preferred choice in Madagascar $(67 \%, 95 \%$ CI: $65 \%$ to $69 \%)$, Malawi $(56 \%, 95 \%$ CI: $54 \%, 57 \%$ ), Kenya (52\%, $95 \%$ CI: $46 \%$ to $58 \%$ ), Gambia (51\%, $95 \%$ CI: $46 \%$ to $56 \%)$, Sierra Leone $(50 \%, 95 \%$ CI: $47 \%$ to $53 \%$ ) and Mali (40\%, 95\% CI: $37 \%$ to $43 \%$ ). Oral pills were a more preferred choice in Sudan $(84 \%$, $95 \%$ CI: $81 \%$ to $87 \%$ ), Mauritania (68\%, $95 \%$ CI: $63 \%$ to $72 \%)$, Zimbabwe (60\%, $95 \%$ CI: $58 \%$ to $62 \%)$, Tunisia

\begin{tabular}{|c|c|c|c|}
\hline Country & Year & $\begin{array}{l}\text { Sample } \\
\text { size }\end{array}$ & $\begin{array}{l}\% \\
\text { Sample }\end{array}$ \\
\hline DRC & 2017-2018 & 91659 & 7.8 \\
\hline Gambia & 2018 & 56438 & 4.8 \\
\hline Ghana & 2017-2018 & 52930 & 4.5 \\
\hline Lesotho & 2018 & 21223 & 1.8 \\
\hline Madagascar & 2018 & 67592 & 5.7 \\
\hline Sierra Leone & 2017 & 65671 & 5.6 \\
\hline Togo & 2017 & 28142 & 2.4 \\
\hline Tunisia & 2018 & 35164 & 3.0 \\
\hline Benin & 2014 & 63405 & 5.4 \\
\hline Guinea Bissau & 2014 & 42326 & 3.6 \\
\hline Cameroon & 2014 & 37648 & 3.2 \\
\hline Guinea & 2016 & 40901 & 3.5 \\
\hline Côte d'Ivoire & 2016 & 46503 & 3.9 \\
\hline $\begin{array}{l}\text { Kenya (Kakamega } \\
\text { county) }\end{array}$ & 2013-2014 & 3917 & 0.3 \\
\hline Malawi & 2013-2014 & 100324 & 8.5 \\
\hline Mali & 2015 & 88434 & 7.5 \\
\hline Mauritania & 2015 & 58436 & 5.0 \\
\hline Nigeria & 2016-2017 & 143447 & 12.2 \\
\hline Sudan & 2014 & 81398 & 6.9 \\
\hline Zimbabwe & 2014 & 51901 & 4.4 \\
\hline Total & & 1177459 & 100.0 \\
\hline
\end{tabular}

DRC, Democratic Republic of Congo; MICSs, Multiple Indicator Cluster Surveys.

(49\%, $95 \%$ CI: $47 \%$ to $52 \%)$ and Côte d'Ivoire $(40 \%$, 95\% CI: $36 \%$ to $44 \%$ ). Implants were more commonly used in the Gambia (33\%, $95 \%$ CI: $28 \%$ to $38 \%$ ), Mali (33\%, $95 \%$ CI: $29 \%$ to $36 \%)$, Guinea Bissau (25\%, 95\% CI: $22 \%$ to $28 \%)$, Benin (24\%, $95 \%$ CI: $21 \%$ to $27 \%)$ and Togo (24\%, $95 \%$ CI: $20 \%$ to $28 \%$ ), while condoms were more preferred in Cameroon (69\%, 95\% CI: $66 \%$ to $72 \%)$, DRC ( $45 \%$, 95\% CI: $39 \%$ to $50 \%)$, Guinea Bissau (37\%, 95\% CI: $33 \%$ to $40 \%)$, Lesotho (31\%, $95 \%$ CI: $28 \%$ to $34 \%)$ and Togo (25\%, 95\% CI: $22 \%$ to $29 \%)$. There was high heterogeneity among modern CP methods across all countries as follows: sterilisation $\left(\mathrm{I}^{2}=97.7 \%\right.$, $\mathrm{p}$ value $<0.001)$, injectable $\left(\mathrm{I}^{2}=99.8 \%\right.$, $\mathrm{p}$ value $\left.<0.001\right)$, pills $\left(I^{2}=99.8 \%\right.$, p value $\left.<0.001\right)$, condoms $\left(I^{2}=99.5 \%\right.$, $\mathrm{p}$ value $<0.001)$, IUD $\left(\mathrm{I}^{2}=99.0 \%, \mathrm{p}\right.$ value $\left.<0.001\right)$ and implants $\left(\mathrm{I}^{2}=99.0 \%\right.$, $\mathrm{p}$ value $\left.<0.001\right)$. However, there was low heterogeneity in the prevalence of diaphragm/foam/ jelly across the 20 countries $\left(I^{2}=69.0 \%\right.$, p value $\left.<0.001\right)$.

Factors associated with the use of modern CPs among women The aPORs of independent variables and modern CP use by each country can be seen in the online supplemental table 1 . The results of our meta-analysis showed 


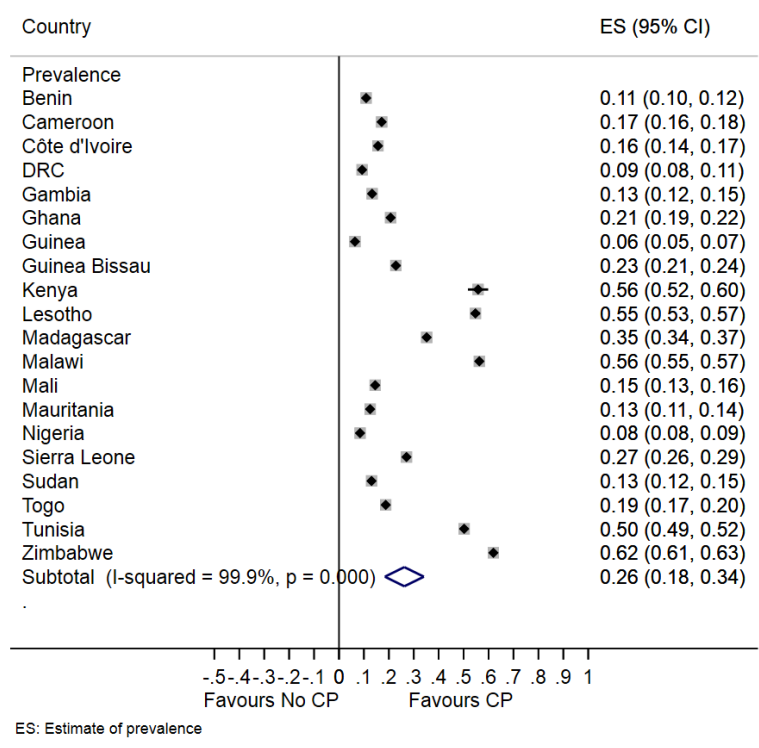

Figure 1 Prevalence of modern contraceptive (CP) use. DRC, Democratic Republic of Congo.

that women with primary (aPORs: $1.68,95 \%$ CI: 1.47 to 1.91)) and secondary or higher education (aPOR: 2.16, $95 \%$ CI: 1.80 to 2.59 ) were more likely to use modern CPs compared with women without a formal education. Older women aged 25-34 years had 33\% higher odds of modern CP use compared with younger women aged 15-24 years (aPOR: 1.33 , 95\% CI: 1.20 to 1.47 ). The prevalence of modern CP use was similar between women aged 35-49 and women aged 15-24 years (aPOR: 0.89, 95\% CI: 0.74 to 1.06 ) (figure 4 ). Women who were rich and of middle-income status had $53 \%$ and $25 \%$ higher odds of CP use, respectively, when compared with poor women. Women who were never married had $35 \%$ lower odds of use of CPs compared with women who were married women. Our results also showed that women from rural settings had $13 \%$ lower odds of modern CP use compared with women living in urban areas (figure 5).

Women who received antenatal care on two, three and on four or more visits, respectively, had 2.27, 2.37 and 2.84 times the odds of using CPs compared with women who did not receive an antenatal care. However, receiving antenatal care on only one visit was not associated with modern CP use (figure 6). Additionally, women who had not delivered in the last 2 years were more likely to use modern CPs compared with women who delivered within the last 2 years (aPOR: 3.89, 95\% CI: 2.76 to 5.47 ). No access to media among women reduced the odds of using CPs by $18 \%$ compared with women with access to media. Nulliparous women had $89 \%$ lower odds of CP use compared with parous women. Also, being a registered health insurance member and perceived domestic violence were not associated with use of modern CPs (figure 7).

\section{DISCUSSION}

Our analysis found that overall prevalence of modern CP use was low and varied across the 20 countries. Overall, injectable was the most preferred method of modern CP followed by oral pills and implants. Factors positively associated with modern CP use were: primary education, secondary or higher education, two or more antenatal care visits, no delivery in the last 2 years, women aged 25-34 years and women of middle- and high-income status. We found that women living in rural settings, never married, no access to the media and nulliparous women were less likely to use modern CPs. However, perceived domestic violence and being a registered health insurance member were not associated with modern CP use.

There has been an appreciable increase in modern CP use over the past 30 years consistent with behavioural change and ongoing family planning programmes. ${ }^{26}$ However, our study found that the overall use of modern CP still remains low in Africa. This latest finding is consistent with similar studies that reported low level of CP use within the African region. ${ }^{15}$ It is therefore not surprising that the scale-up of CPs in Africa has been recommended to avert unintended pregnancies and maternal mortality. ${ }^{47}$ The variation in prevalence of modern CP use by country in our study might reflect the differences in culture, religion and family planning service delivery among African countries. ${ }^{28}$ The high prevalence of modern CP use in Zimbabwe could be due to the high prevalence of secondary and higher education coupled with the sound foundation for motivating women to use CPs. ${ }^{29}$ Our finding on injectable being the most preferred method of modern $\mathrm{CP}$ is consistent with findings from similar studies completed in Africa. ${ }^{13} 1530$

We found that women aged 25-34 years were more likely to use CPs compared with women aged 15-24 years. One possible explanation to this is that women aged 15-24 years might not have better understanding of the consequences of engaging in unprotected sex or the benefits of the CP use as compared with women aged 25-34 years. $^{31} 32$ This reflects the high rates of teenage pregnancy across Africa. ${ }^{32}$ Our findings on the positive association between women with at least a primary education and modern CP use are corroborate with many previous African-based studies. ${ }^{30} 313334$ This is not surprising because education helps women to be well informed on the benefits of CPs. It also empowers them to have the autonomy to make decisions on their fertility, and in the exercise of their reproductive rights. ${ }^{31}$ With regards to the finding on the relationship between economic class and CP use, our study demonstrates that women of highand middle-income class status were more likely to use CPs as compared with poor women. This is as a result of the financial barriers that exist in Africa, limiting poor women from having easy access to CP services and education. $^{1235}$

Our analysis showed that two or more antenatal care visits were associated with modern CP. Like many other studies, this observed association is not unique to our 


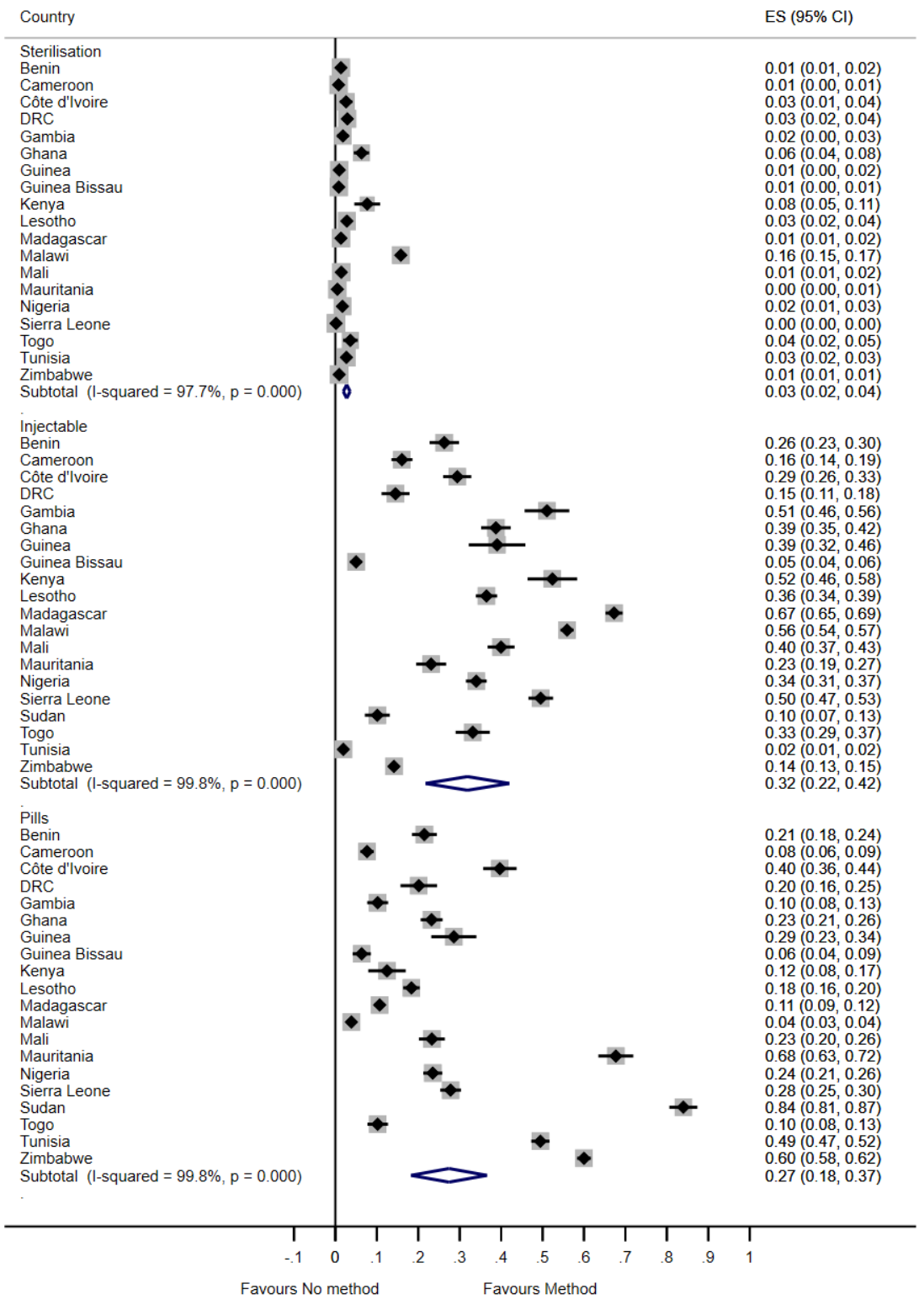

ES: Estimate of prevalence; Sudan:No report on sterilisation

Figure 2 Prevalence of method of modern contraceptive use. DRC, Democratic Republic of Congo.

study. ${ }^{36}{ }^{37}$ Antenatal care represents a unique opportunity to interact, educate and provide family support to women from diverse socioeconomic status, and this facilitates the uptake of modern CPs. ${ }^{38}$ This finding, which adds to the existing literature, provides a benchmark for integrating family planning services during antenatal care to improve maternal and child health outcomes. ${ }^{39} \mathrm{In}$ our study, women who had no delivery in the last 2 years were more likely to use CPs when compared with their peers that delivered within the last 2 years. This finding is interesting and has maternal and child health implications for women who delivered within the last 2 years, and do not use CPs. In theory, we would expect women to engage in $\mathrm{CP}$ use within this period to reduce the risk of neonatal mortality and preeclampsia. ${ }^{40}$ Timely use of CPs is therefore critical for women to space their children, and helps improve their health and their ability to take care of their children. ${ }^{41}$ We also observed in our study that nulliparous women were less likely to use CPs than parous women. This finding is consistent with previous studies, ${ }^{1642}$ but contrary to the findings of Geremew and Gelagay. ${ }^{34}$

In the results, we reported that women resident in rural settings were associated with reduced use of CPs compared with their colleagues from urban settings. This finding has also been reported in previous studies. ${ }^{3138}$ The increase in use of CPs among women in urban settings might be due to experience of late marriage as compared with their counterparts in rural settings. ${ }^{43}{ }^{44}$ We further reported that women who were never married were less 


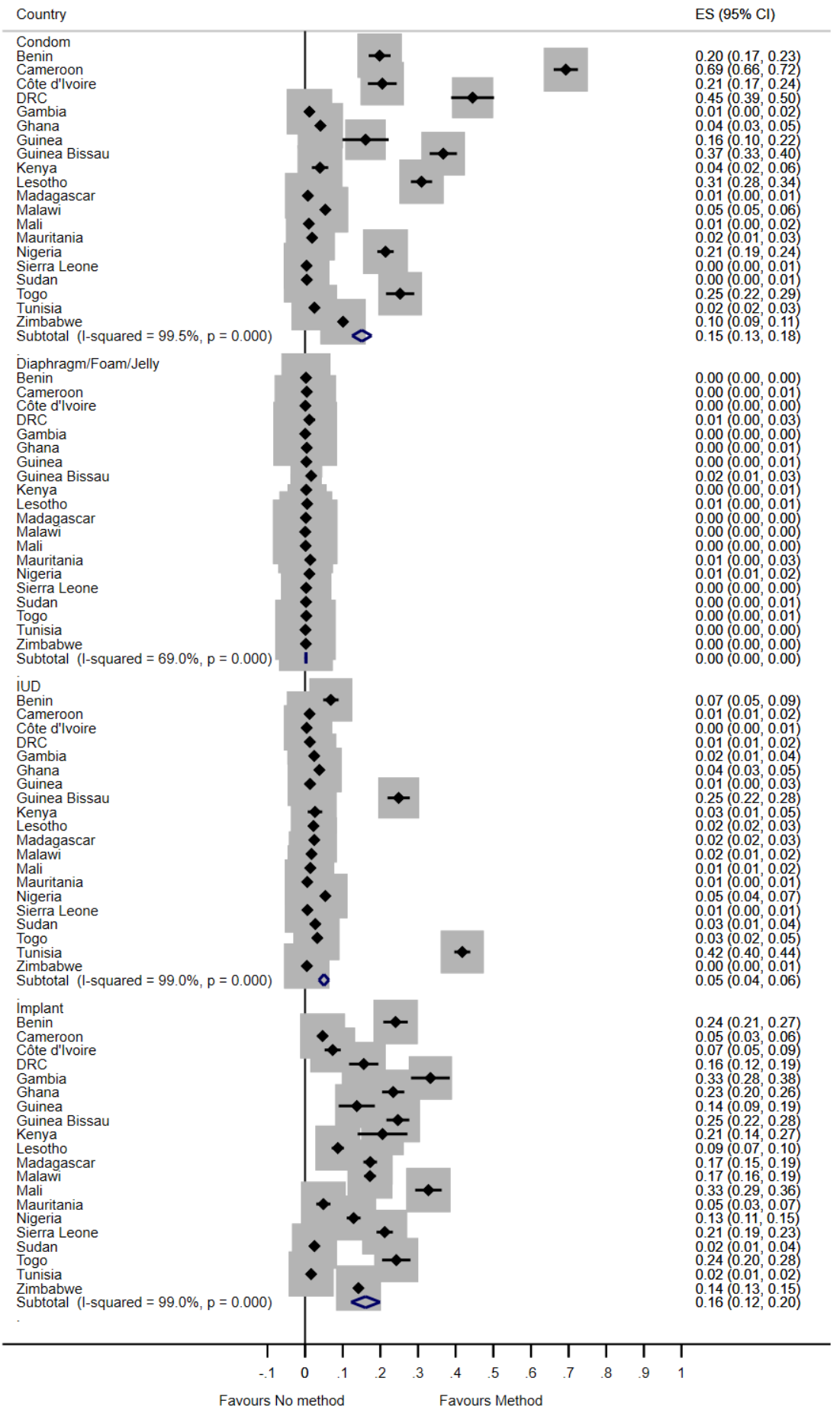

ES: Estimate of prevalence

Figure 3 Prevalence of method of modern contraceptive use. DRC, Democratic Republic of Congo; IUD, intrauterine device.

likely to use CPs than married women. Our reported finding is contrary to recent findings of $\mathrm{Ba} e t a l$ s study which examined any form of CP use. ${ }^{15}$

The media (ie, print and electronic) plays a role in promoting public health in Africa. Studies on the role of media have revealed that access to radios, televisions and newspapers increased CP use among women. ${ }^{45} 46$ In our study, we found that women with no access to media were less likely to use modern CPs compared with women that had access to the media. In their study, Islam et al concluded that television, radio and the print media should be adopted in the dissemination of family planning messages. ${ }^{45}$ Our study also revealed that being a registered health insurance status member was not 


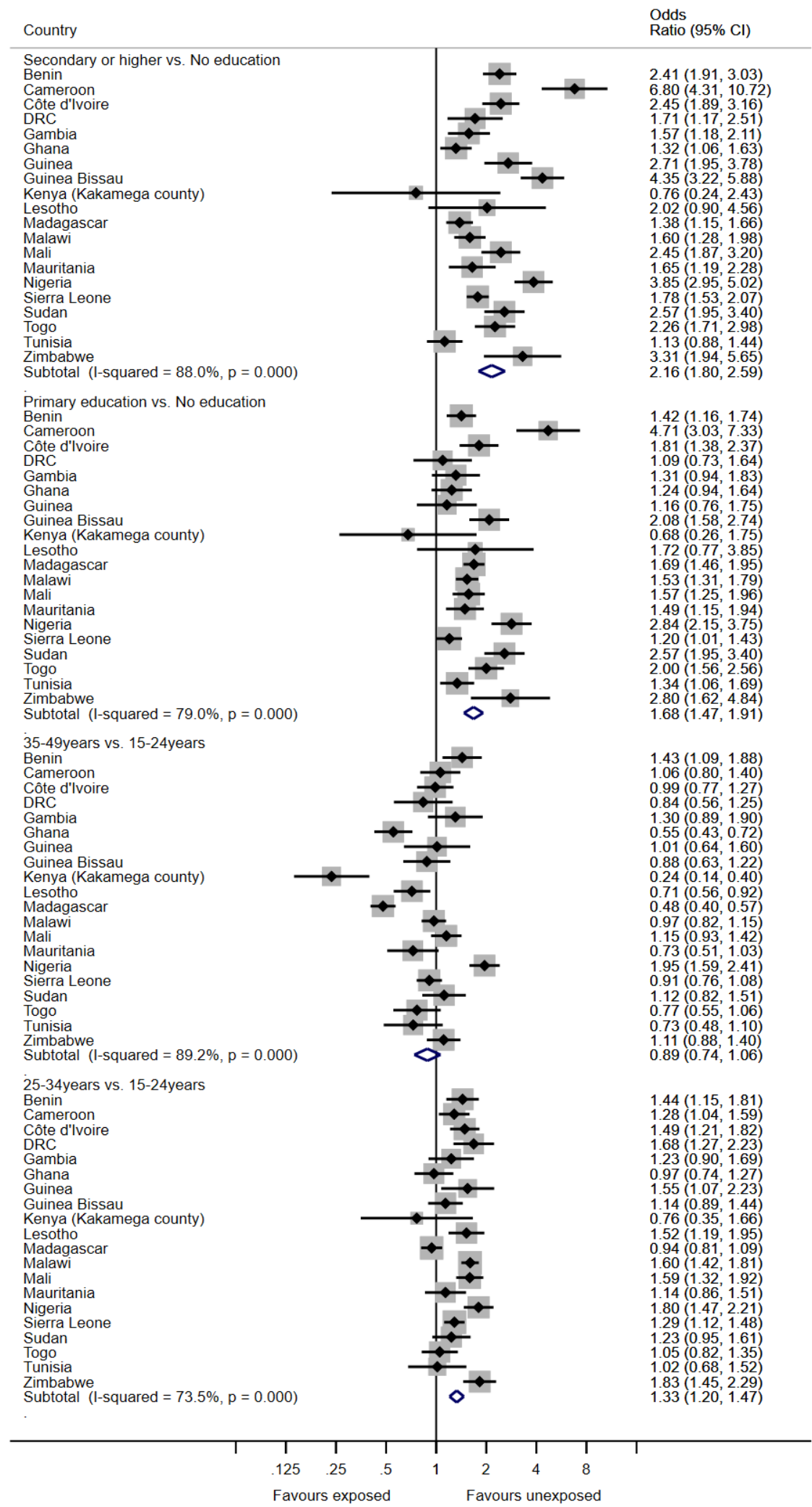

Figure 4 The association between age, educational level and use of modern contraceptives. DRC, Democratic Republic of Congo. 


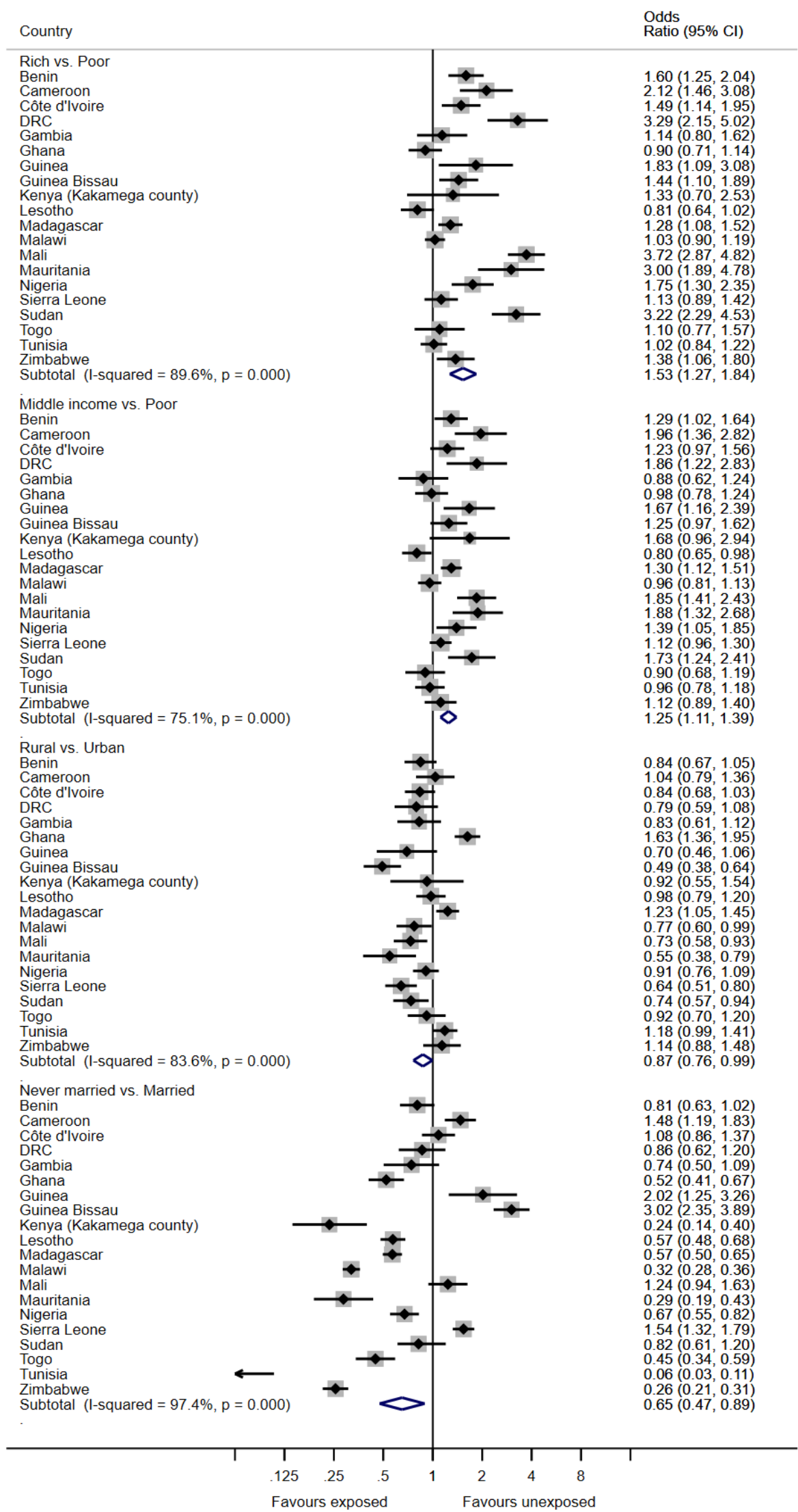

Figure 5 The association between wealth status, residency status, marital status and use of modern contraceptives. DRC, Democratic Republic of Congo. 


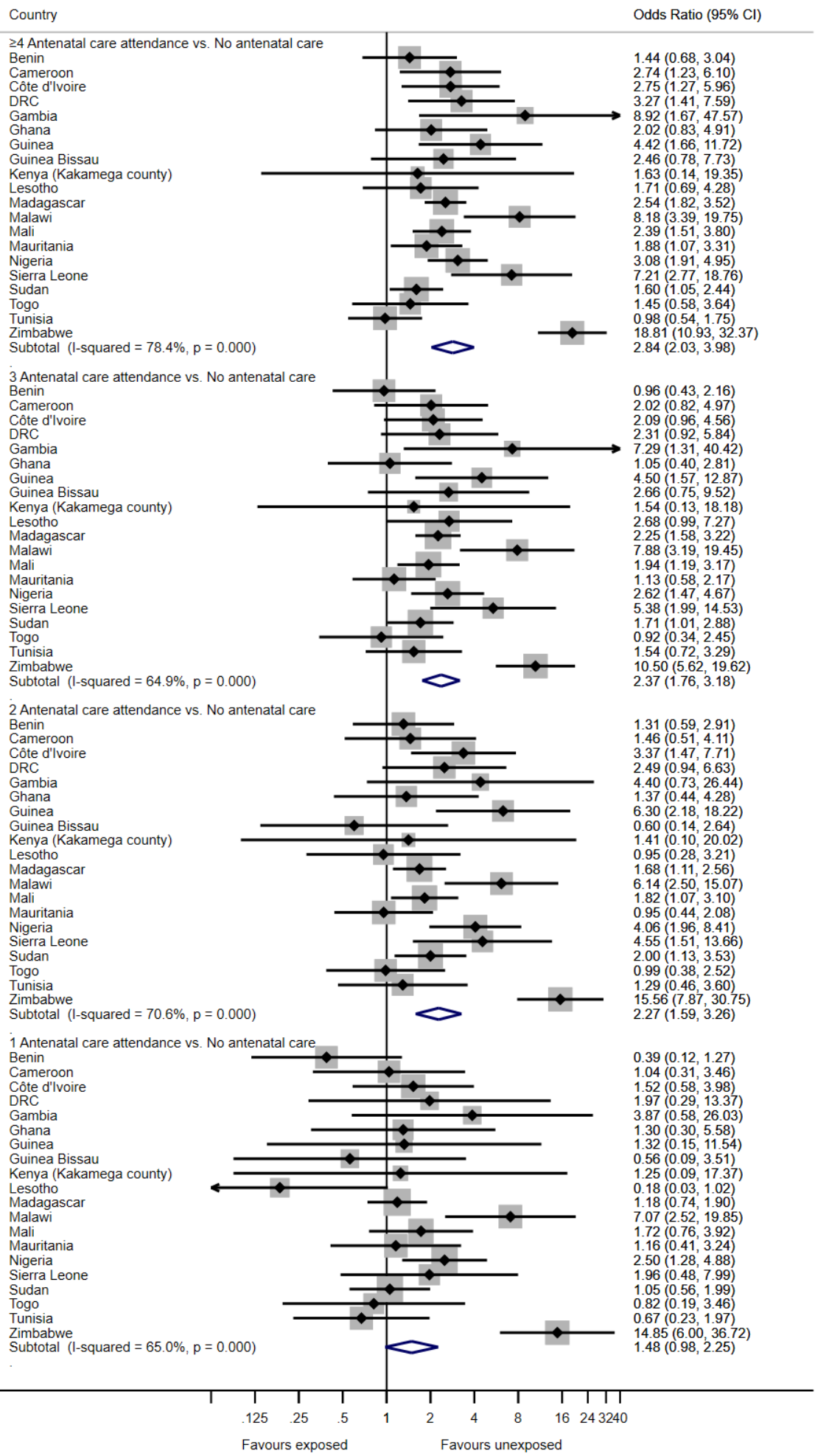

Figure 6 The association between antenatal care attendance and use of modern contraceptives. DRC, Democratic Republic of Congo.

independently associated with modern $\mathrm{CP}$ use. This finding might be due to the free or subsidised CPs offered to clients in some African countries, and is likely to close the differences in the cost of obtaining a CP between clients with and without a health insurance. ${ }^{47-49}$ Our null finding on the association between perceived domestic violence and modern $\mathrm{CP}$ use is unique. To the best of our knowledge, there has not been a large 


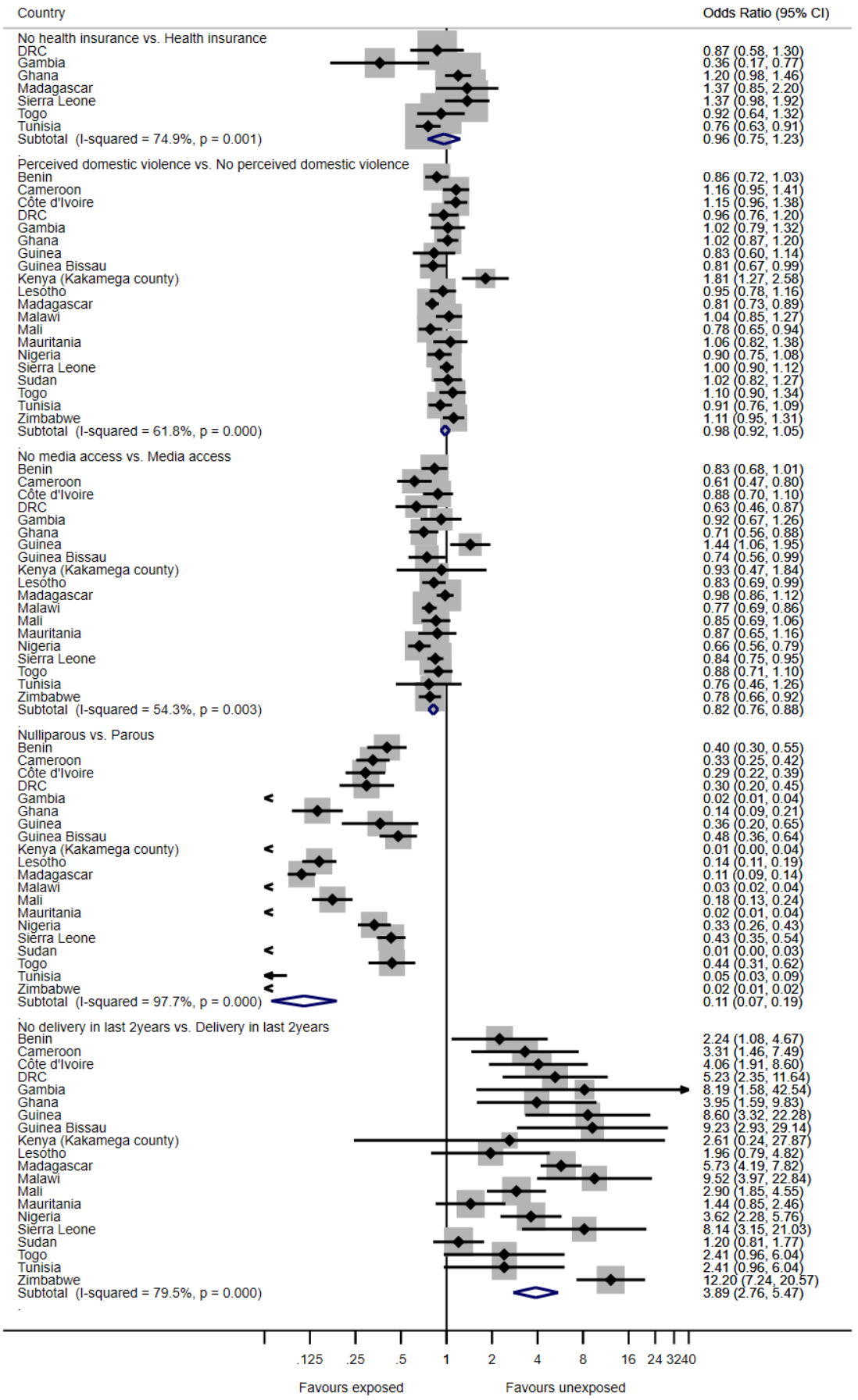

Only seven countries had data on health insurnce status; Sudan:No report on access to media

Figure 7 The association between health insurance status, perceived domestic violence, access to media, parity, period of delivery and use of modern contraceptives. DRC, Democratic Republic of Congo.

population-based study in the African context that has examined the influence of perceived domestic violence on modern CP use among women of reproductive age, though studies on domestic violence on CPs use more generally have been reported. ${ }^{50}{ }^{51}$ This finding may imply that women recognise the importance of modern CPs, and therefore perceived domestic violence may not play a role in its usage. It may also suggest that women in Africa do not understand what constitutes domestic violence as women have reportedly argued that they deserve the beatings meted out to them by their husbands/partners for behaviours they exhibited. ${ }^{52} 53$

Our study had some strengths and limitations. Our findings can be generalised to the African region, and other similar low-middle-income developing country settings. The main limitation however is that our study 
was cross-sectional, and we cannot establish causality. Another limitation is that some of our independent variables were self-reported, and thus are subject to recall bias. We expect recall bias to be similar between women on modern CPs, and those not on it. However, we expect less recall bias on our primary outcome as it was measured on the current use of modern CPs. There was also high heterogeneity between many of the countries for most of our variables. Though some have argued against pooling with high heterogeneity, pooling may still be very appropriate for our study. ${ }^{54}$ One other limitation is that, data in Kenya were only in one county (Kakamega), and therefore findings may not be generalisable to Kenya.

\section{CONCLUSION}

Our findings showed low overall prevalence of modem CP use with variation among the 20 African countries. The preference of method of $\mathrm{CP}$ also varied among countries. We found that primary education, secondary or higher education, two or more antenatal care visits, no delivery in the last 2 years, women aged 25-34 years and women of middle-income and high-income status were positively associated with modern CP use. We recommend that African Governments should strengthen their family planning programmes with a focus on making family planning information more accessible. Education should also be intensified during the postnatal period on the importance of birth spacing to improve maternal and child health outcomes. Encouraging pregnant women participation in antenatal care is also relevant for increasing the coverage of modern CPs.

Acknowledgements We are grateful to the UNICEF Multiple Indicator Cluster Surveys team for the making the data available to us.

Contributors PAA, MTK and EAA conceived the study. PAA conducted the data analysis. PAA, MTK, EAA and MBU wrote the manuscript and critically reviewed the manuscript for its intellectual content. RA provided intellectual guidance. All authors read and approved the manuscript for submission.

Funding The authors have not declared a specific grant for this research from any funding agency in the public, commercial or not-for-profit sectors.

Competing interests None declared.

Patient and public involvement Patients and/or the public were not involved in the design, or conduct, or reporting, or dissemination plans of this research.

Patient consent for publication Not required.

Ethics approval This study did not require ethics approval as we used secondary data that are publicly available. Details of ethics approval for Multiple Indicator Cluster Surveys are available at: https://mics.unicef.org/tools.

Provenance and peer review Not commissioned; externally peer reviewed.

Data availability statement Data are available in a public, open access repository. Multiple Indicator Cluster Surveys data are publicly available at:https://mics.unicef. org/surveys.

Open access This is an open access article distributed in accordance with the Creative Commons Attribution Non Commercial (CC BY-NC 4.0) license, which permits others to distribute, remix, adapt, build upon this work non-commercially, and license their derivative works on different terms, provided the original work is properly cited, appropriate credit is given, any changes made indicated, and the use is non-commercial. See: http://creativecommons.org/licenses/by-nc/4.0/.
ORCID iD

Paschal Awingura Apanga http://orcid.org/0000-0003-0038-3630

\section{REFERENCES}

1 WHO. Contraception: evidence brief, 2019. Available: https://apps. who.int/iris/bitstream/handle/10665/112319/WHO_RHR_14.07_eng. pdf?ua=. [Accessed 12 May 2020].

2 Wang W, Staveteig S, Winter R, et al. Women's Marital Status, Contraceptive Use, and Unmet Need in Sub-Saharan Africa, Latin America, and the Caribbean, 2017. Available: https://dhsprogram. com/pubs/pdf/CR44/CR44.pdf [Accessed 12 May 2020].

3 Beson P, Appiah R, Adomah-Afari A. Modern contraceptive use among reproductive-aged women in Ghana: prevalence, predictors, and policy implications. BMC Womens Health 2018;18:157.

4 Ahmed S, Li Q, Liu L, et al. Maternal deaths averted by contraceptive use: an analysis of 172 countries. Lancet 2012;380:111-25.

5 Seltzer JR. The origins and evolution of family planning programs in developing countries. RAND Corporation, 2002.

6 Nonvignon J, Novignon J. Trend and determinants of contraceptive use among women of reproductive age in Ghana. African Population Studies 2014;28:956-67.

7 Dockalova B, Lau K, Barclay $\mathrm{H}$, et al. Sustainable development goals and family planning 2020, 2016. Available: https://www.ippf.org/ sites/default/files/2016-11/SDG\%20and\%20FP2020.pdf [Accessed 12 May 2020].

8 Slaymaker E, Scott RH, Palmer MJ, et al. Trends in sexual activity and demand for and use of modern contraceptive methods in 74 countries: a retrospective analysis of nationally representative surveys. Lancet Glob Health 2020;8:e567-79.

9 Cahill N, Sonneveldt E, Stover J, et al. Modern contraceptive use, unmet need, and demand satisfied among women of reproductive age who are married or in a union in the focus countries of the family planning 2020 initiative: a systematic analysis using the family planning estimation tool. Lancet 2018;391:870-82.

10 Aviisah PA, Dery S, Atsu BK, et al. Modern contraceptive use among women of reproductive age in Ghana: analysis of the 2003-2014 Ghana demographic and health surveys. BMC Womens Health 2018;18:141.

11 Ahmed S, Choi Y, Rimon JG, et al. Trends in contraceptive prevalence rates in sub-Saharan Africa since the 2012 London Summit on family planning: results from repeated cross-sectional surveys. Lancet Glob Health 2019;7:e904-11.

12 Adebowale SA, Adedini SA, Ibisomi LD, et al. Differential effect of wealth quintile on modern contraceptive use and fertility: evidence from Malawian women. BMC Womens Health 2014;14:40.

13 Tsui AO, Brown W, Li Q. Contraceptive practice in sub-Saharan Africa. Popul Dev Rev 2017;43:166-91.

14 Morris N, Prata N. Abortion history and its association with current use of modern contraceptive methods in Luanda, Angola. Open Access J Contracept 2018;9:45-55.

$15 \mathrm{Ba}$ DM, Ssentongo P, Agbese E, et al. Prevalence and predictors of contraceptive use among women of reproductive age in 17 sub-Saharan African countries: a large population-based study. Sex Reprod Healthc 2019;21:26-32.

16 Gebre MN, Edossa ZK. Modern contraceptive utilization and associated factors among reproductive-age women in Ethiopia: evidence from 2016 Ethiopia demographic and health survey. BMC Womens Health 2020;20:61.

17 Khan S, Hancioglu A. Multiple indicator cluster surveys: delivering robust data on children and women across the globe. Stud Fam Plann 2019;50:279-86.

18 UNICEF. Multiple indicator cluster survey (MICs), 2019. Available: https://mics.unicef.org/ [Accessed 23 Dec 2019].

19 National Bureau of Statistics and UNICEF. Multiple indicator cluster survey 2016-2017, survey findings report. Abuja, Nigeria, 2017.

20 Singh S, Darroch J, Ashford L. Adding it up: the costs and benefits of investing in sexual and reproductive health. New York: Guttmacher Institute and United nations population fund, 2014. Available: https:// www.unfpa.org/sites/default/files/pub-pdf/Adding\%20lt\%20UpFinal-11.18.14.pdf [Accessed 16 Jul 2020].

21 Hubacher D, Trussell J. A definition of modern contraceptive methods. Contraception 2015;92:420-1.

22 Donovan $P$, Wulf $D$. Family planning can reduce high infant mortality levels. Issues Brief 2002:1-4.

23 Lutalo T, Gray R, Santelli J, et al. Unfulfilled need for contraception among women with unmet need but with the intention to use contraception in Rakai, Uganda: a longitudinal study. BMC Womens Health 2018;18:60. 
24 Uddin J, Hossin MZ, Pulok MH. Couple's concordance and discordance in household decision-making and married women's use of modern contraceptives in Bangladesh. BMC Womens Health 2017;17:107.

25 Higgins J, Green S. Cochrane Handbook for systematic reviews of interventions. Wiley Online Library, 2008.

26 Emina JBO, Chirwa T, Kandala N-B. Trend in the use of modern contraception in sub-Saharan Africa: does women's education matter? Contraception 2014;90:154-61.

27 Hubacher D, Mavranezouli I, McGinn E. Unintended pregnancy in sub-Saharan Africa: magnitude of the problem and potential role of contraceptive implants to alleviate it. Contraception 2008;78:73-8.

28 Srikanthan A, Reid RL. Religious and cultural influences on contraception. J Obstet Gynaecol Can 2008;30:129-37.

29 Mturi A, Joshua K. Falling fertility and increase in use of contraception in Zimbabwe. Afr J Reprod Health 2011;15:31-44.

30 Lunani LL, Abaasa A, Omosa-Manyonyi G. Prevalence and factors associated with contraceptive use among Kenyan women aged 1549 years. AIDS Behav 2018;22:125-30.

31 Mandiwa C, Namondwe B, Makwinja A, et al. Factors associated with contraceptive use among young women in Malawi: analysis of the 2015-16 Malawi demographic and health survey data. Contracept Reprod Med 2018;3:12.

32 Kassa GM, Arowojolu AO, Odukogbe AA, et al. Prevalence and determinants of adolescent pregnancy in Africa: a systematic review and meta-analysis. Reprod Health 2018;15:195.

33 Blackstone SR, Nwaozuru U, Iwelunmor J. Factors influencing contraceptive use in sub-Saharan Africa: a systematic review. Int $Q$ Community Health Educ 2017;37:79-91.

34 Geremew AB, Gelagay AA. Modern contraceptive use and associated factors among married women in Finote Selam town Northwest Ethiopia: a community based cross-sectional study. Womens Midlife Health 2018;4:13.

35 Haider TL, Sharma M. Barriers to family planning and contraception uptake in sub-Saharan Africa: a systematic review. Int Q Community Health Educ 2012;33:403-13.

36 Emiru AA, Alene GD, Debelew GT. The role of maternal health care services as predictors of time to modern contraceptive use after childbirth in Northwest Ethiopia: Application of the shared frailty survival analysis. PLoS One 2020;15:e0228678.

37 RamaRao S, Ishaku S, Liambila W, et al. Enhancing contraceptive choice for postpartum women in sub-Saharan Africa with the progesterone vaginal ring: a review of the evidence. Open Access $J$ Contracept 2015;6:117-23.

38 Agha S, Williams E. Does the antenatal care visit represent a missed opportunity for increasing contraceptive use in Pakistan? an analysis of household survey data from Sindh Province. Health Policy Plan 2016;31:325-31.

39 Ahmed S, Norton M, Williams E, et al. Operations research to add postpartum family planning to maternal and neonatal health to improve birth spacing in Sylhet district, Bangladesh. Glob Health Sci Pract 2013;1:262-76.

40 Julie D, Abdur R, Mizanaur R, et al. The Effects of Birth Spacing on Infant and Child Mortality, Pregnancy Outcomes, and Maternal Morbidity and Mortality in Matlab, Bangladesh., 2004. Available: https://www.rand.org/content/dam/rand/pubs/working_papers/2004/ RAND_WR198.pdf [Accessed 7 May 2020].

41 Keesara S, Juma PA, Harper CC, et al. Barriers to postpartum contraception: differences among women based on parity and future fertility desires. Cult Health Sex 2018;20:247-61.

42 Lasong J, Zhang Y, Gebremedhin SA, et al. Determinants of modern contraceptive use among married women of reproductive age: a cross-sectional study in rural Zambia. BMJ Open 2020;10:e030980.

43 White JS, Speizer IS. Can family planning outreach bridge the urbanrural divide in Zambia? BMC Health Serv Res 2007;7:143.

44 Pradhan R, Wynter K, Fisher J. Factors associated with pregnancy among adolescents in low-income and lower middle-income countries: a systematic review. J Epidemiol Community Health 2015;69:918-24.

45 Islam MR, Islam MA, Banowary B. Determinants of exposure to mass media family planning messages among Indigenous people in Bangladesh: a study on the Garo. J Biosoc Sci 2009;41:221-9.

46 Westoff $\mathrm{C}$, Rodriguez $\mathrm{G}$. The mass media and family planning in Kenya. International Family Planning Perspectives 1995;21.

47 Beekle AT, McCabe C. Awareness and determinants of family planning practice in Jimma, Ethiopia. Int Nurs Rev 2006;53:269-76.

48 Abdul-Rahman L, Marrone G, Johansson A. Trends in contraceptive use among female adolescents in Ghana. Afr J Reprod Health 2011;15:45-55.

49 Robinson AL, Seiber EE. Does community clustering mitigate the negative effect of poverty on adolescent condom use in South Africa? Int Fam Plan Perspect 2008;34:121-6.

50 Olorunsaiye CZ, Brunner Huber L, Laditka SB, et al. Associations between women's perceptions of domestic violence and contraceptive use in seven countries in West and central Africa. Sex Reprod Healthc 2017;13:110-7.

51 Wandera SO, Kwagala B, Odimegwu C. Intimate partner violence and current modern contraceptive use among married women in Uganda: a cross-sectional study. Pan Afr Med J 2018;30:85.

52 Bamiwuye SO, Odimegwu C. Spousal violence in sub-Saharan Africa: does household poverty-wealth matter? Reprod Health 2014;11:45

53 Laisser RM, Nyström L, Lugina HI, et al. Community perceptions of intimate partner violence--a qualitative study from urban Tanzania. BMC Womens Health 2011;11:13.

54 Caldwell DM, Welton NJ. Approaches for synthesising complex mental health interventions in meta-analysis. Evid Based Ment Health 2016;19:16-21. 